Synchrotron-based tomographic microscopy (SbTM) of wood Development of a testing device and observation of plastic deformation of uniaxially compressed Norway spruce samples

\author{
Journal Article \\ Author(s): \\ Zauner, Michaela; Keunecke, Daniel; Stampanoni, Marco; Niemz, Peter \\ Publication date: \\ 2012-12 \\ Permanent link: \\ https://doi.org/10.3929/ethz-b-000058980
}

Rights / license:

In Copyright - Non-Commercial Use Permitted

Originally published in:

Holzforschung 66(8), https://doi.org/10.1515/hf-2011-0192 


\section{Synchrotron-based tomographic microscopy (SbTM) of wood: development of a testing device and observation of plastic deformation of uniaxially compressed Norway spruce samples}

\author{
Michaela Zauner ${ }^{1, *}$, Daniel Keunecke ${ }^{1}$, \\ Rajmund Mokso², Marco Stampanoni² \\ and Peter Niemz ${ }^{1}$ \\ ${ }^{1}$ Department of Civil, Environmental and Geomatic \\ Engineering, Institute for Building Materials, ETH \\ Zurich, Zurich, Switzerland \\ ${ }^{2}$ Paul Scherrer Institut, SLS, Villigen, Switzerland \\ * Corresponding author. \\ Department of Civil, Environmental and Geomatic Engineering, \\ Institute for Building Materials, ETH Zurich, 8093 Zurich, \\ Switzerland \\ Phone: +41-44-632-5231 \\ Fax: +41-44-632-1174 \\ E-mail: mzauner@ethz.ch
}

\begin{abstract}
To understand better the structure-property relationships of wood in situ, nondestructive synchrotron-based tomographic microscopy (SbTM) with subcellular resolution is useful. In this context, an in situ testing device was developed to determine the cellular response of wood to mechanical loading. Different rotationally symmetric specimens were tested to synchronize the failure areas to the given scanning areas. Norway spruce samples were uniaxially compressed in the longitudinal direction and scanned in situ at several increasing relative forces ending up in the plastic deformation regime. A sufficiently high quality in situ tomography was demonstrated. The reconstructed data allowed the observation of the load-dependent development of failure regions: cracks and buckling on the microstructure were clearly visible. Future investigations with SbTM on different wood species, loading directions, and different moisture contents are promising in terms of the micromechanical behavior of wood.
\end{abstract}

Keywords: compression; in situ tests; Norway spruce; synchrotron-based tomographic microscopy (SbTM); synchrotron radiation micro computed tomography $(\mathrm{SR} \mu \mathrm{CT})$.

\section{Introduction}

Mechanical properties of wood are influenced by the composition and structure of its anatomical elements at the microscopic and macroscopic level. Softwoods consist of $90 \%$ tube-shaped tracheids and $10 \%$ of brick-shaped parenchyma cells as part of the wood rays (Wagenführ 2007). On the mesoscopic scale, a growth ring is composed of thin-walled earlywood (EW) tracheids and thick-walled latewood (LW) tracheids. The composition of wood is inhomogeneous, and the spatial distribution of the different cell types (and their size) may vary, thus the physical properties of wood observed at the macroscopic level vary significantly even within the same species (Keunecke et al. 2008). This is a reason why the simulations of the mechanical behavior of wood are difficult (Hofstetter et al. 2005). The improved knowledge of structure-property relationships down to the cellular level combined with imaging methods would probably facilitate this situation.

Various imaging methods for the observation of cellular structures at microscopic resolution are available (Butterfield and Meylan 1980). Optical and electron microscopy (EM) are both essential surface evaluation methods for thicker samples, but are also suitable for analysis of deeper layers within thin samples (transmission mode). Classical EM requires high vacuum and surface sputtering of non-conductive materials to obtain high-resolution images of dry samples (Jansen et al. 2008). The development of the environmental scanning electron microscope (ESEM) made possible the analysis of wetter and non-sputtered samples in a low vacuum environment.

The structure-property relationships of wood was investigated by EM and ESEM ex situ and in situ (Tabarsa and Chui 2000; Sippola and Frühmann 2002; Frühmann et al. 2003; Müller et al. 2003; Vasic and Stanzl-Tschegg 2006). While optical microscopy was mainly used for ex situ observations, EM and especially ESEM are very suitable for various in situ experiments to evaluate crack propagation and reaction to load (Sippola and Frühmann 2002; Frühmann et al. 2003; Müller et al. 2003; Vasic and Stanzl-Tschegg 2006). Both methods have certain disadvantages for in situ tests under mechanical load: during sample preparation, defects can be induced (Jansen et al. 2008). To obtain 3D information from the 2D data of EM or optical microscopy, the sample has to be cut into thin slices after experimentation (Dodd 1948). The more convenient X-ray tomography became available only in the last two decades, with the help of which spatial information can be gained, ranging from the classical computed microtomography X-ray (Steppe et al. 2004; Scholz et al. 2010) to synchrotron microtomography. The latter yields the highest possible resolution and high brilliance. The associated data processing allows acquisition of spatial information even of subcellular structures with a resolution of $0.35 \mu \mathrm{m}$ (Groso et al. 2006; Stampanoni et al. 2006a,b) and observations of different anatomical elements. Both methods provided useful data from in situ mechanical experiments with wood (Trtik 
et al. 2007; Walther and Thoemen 2009; Hass et al. 2010; Mannes et al. 2010), either by means of manual or automatic testing devices (Badel et al. 2008; Forsberg et al. 2008). Suitable testing devices seem to be a bottleneck in this type of experiments.

A special device was constructed and a suitable sample geometry was developed with a defined failure area in the field of view of the synchrotron-based tomographic microscopy (SbTM). The goal was to obtain in situ tomographies of a sample submitted to increasing force levels in the longitudinal direction. Preliminary tests were performed on samples with three different geometries. The expectation is that in the future, series of experiments with various parameters can be carried out based on the know-how of the presented preliminary observations.

\section{Material and methods}

\section{Wood samples}

Beams of $10 \mathrm{~mm}$ thickness were turned to cylinders with $4 \mathrm{~mm}$ diameter for all sample shapes (Figure 1); then, the curvature was produced through a copying process with a negative. Six samples $(8 \mathrm{~mm}$ long and mirror-symmetrical through the cross section at the center) made of Norway spruce (Picea abies [L.] Karst) were tested. The top and bottom parts for fixation had the dimensions of $4 \mathrm{~mm}$ diameter with a length of $1.5 \mathrm{~mm}$. The middle part of the specimens with a length of $5 \mathrm{~mm}$ differed between the three geometries. For two of the samples, the center part was cylindrical with a diameter of $1.4 \mathrm{~mm}$ (geometry A and B), one shape connecting the center and the top part with a linear change (geometry A); for the second shape, a curved junction was used (geometry B). In the third sample, a curve with a 3-mm radius connected the top and bottom parts directly (geometry C), with a smallest diameter of $1.4 \mathrm{~mm}$.

\section{Experimental device}

Because of the high energy during the scanning procedure, an externally controlled loading device was necessary to compress a sample in situ. A special device had to be built (Figure 2a) to fit the restrictions at the Tomographic Microscopy and Coherent Radiology Experiments (TOMCAT, PSI, Villigen, Switzerland) beamline with $2 \mathrm{~kg}$ maximum weight of the experimental setup and various spatial restrictions. For a broad range of future applications, the requirements were $12 \mathrm{~mm}$ traveling distance for the crossbeam, possibility of different loading modes, a maximum static load of $1 \mathrm{kN}$, and fast removal of the sample. Controls of the device were implemented into the PSI system, while a different system exists for independent experiments outside the beamline. The travel distance is controlled through the number of steps necessary by the motor. Strain has to be calculated in the tomography due to the indirect length measurement.

The details are visible in Figure $2 \mathrm{~b}$. The bottom part provides the necessary force in the form of rotational movement of a stepper motor (a) and a series of gears (b). The moved threads (c) are connected to a crossbeam. This leads to a longitudinal movement of the crossbeam (d) when the motor rotates. A load cell (e) for the force measurement is placed in the middle of the machine connected to the crossbeam on one side and the sample holder (f) on the other. The second sample holder is connected to the exchangeable tube (h) at the top of the machine. The lower end of the tube is fixed on the upper plate (i) through a thread, while the upper end is connected to the upper sample holder. It acts as the counter hold for the movement of the sample. Owing to the low absorption coefficient of carbon regarding X-rays and because of mechanical stability, carbon fiber was
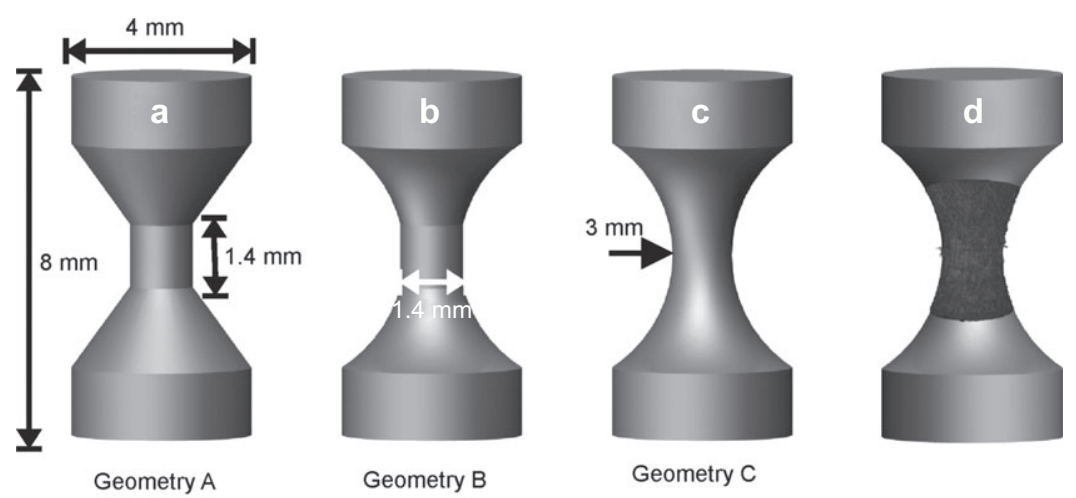

Geometry B

Geometry C

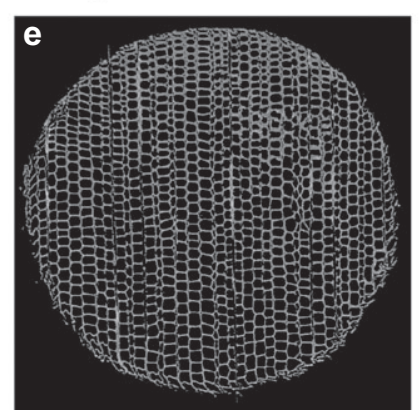

Figure 1 Wood sample geometries with different connections between the bases. (a) Straight, (b) curved to straight, (c) curved, (d) field of view of a sample with regard to the sample size, (e) cross section of compressed sample. 

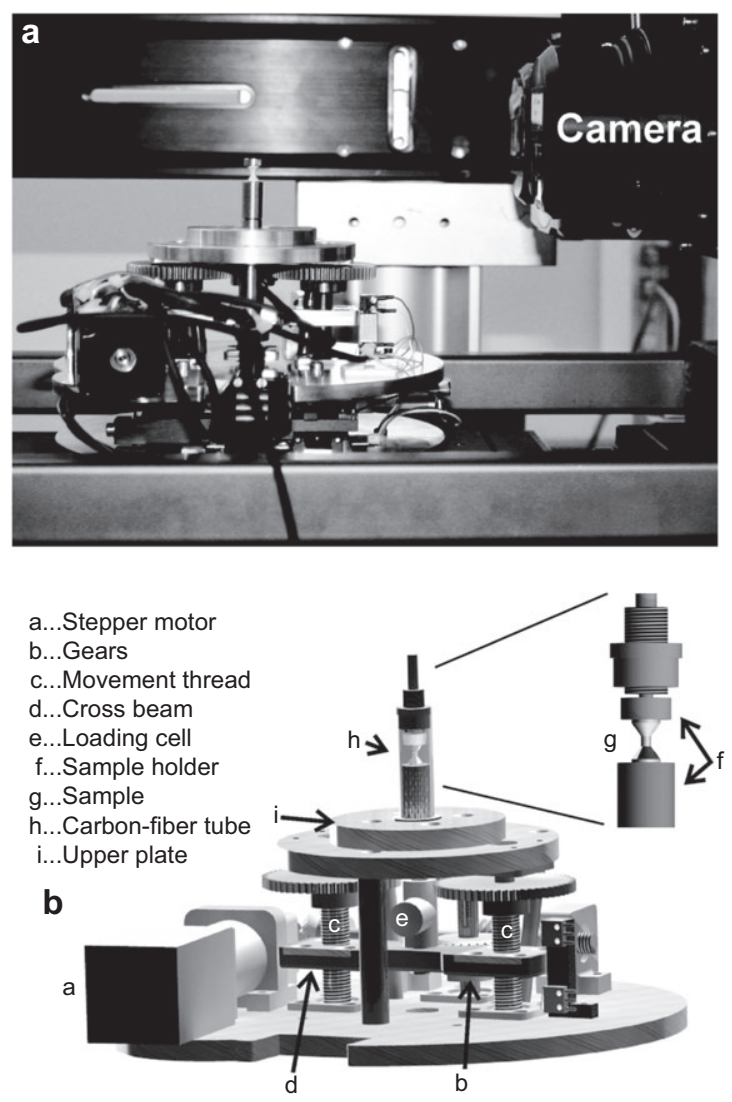

Figure 2 (a) Loading device mounted on the cross table of the beamline - without surrounding tube. (b) CAD design of the testing machine with a close up of the sample holders $-\mathrm{f}$.

used for the tube. For compression, the sample holder consists of two parts with circular cuts with a depth of $1 \mathrm{~mm}$ to center the sample. The upper sample holder possesses a ball joint for the automatic adjustment of the sample while exerting force.

For changing the sample and the loading conditions, the tube has to be removed. The loading case can be changed to tension, compression, and bending by small modifications of the top part of the construction consisting of the tube and the sample holdings. For the time being, the measurements were not as accurate as they should be because of the insufficient insulation of the connecting cables for motor controlling and force measurement.

\section{Scanning procedure}

TOMCAT beamline was adjusted to the lowest possible energy (10 $\mathrm{keV}$ ) in absorption mode. During the recordings, the climate was $23^{\circ} \mathrm{C}$ and $63 \% \mathrm{RH}$. To increase the quality of the recording, the sample was placed as close as possible to the camera for absorption mode. Taking one tomography with 1501 projections, 5 darkfield pictures and 160 flats took $11 \mathrm{~min}$. The camera had a $\times 4$ objective, with a field of view of $3.7 \mathrm{~mm}$ producing a resolution of $1.8 \times 1.8 \times 1.8$ $\mu \mathrm{m}^{3}$ per voxel.

The procedure for a complete loading cycle was identical for all tested sample geometries. First, a preload of $2 \mathrm{~N}$ was applied to ensure fixation and avoid movement of the sample during the first tomography. After taking this tomography that resembled the initial state, the sample was loaded through a movement of the crossbeam over a fixed distance. After reaching the position, the crossbeam stopped while the tomography of the sample was executed. This loading procedure step was repeated until the sample showed a failure area over the whole cross section in the tomography. The distances for each step (except the last) were $0.04 \mathrm{~mm}$ with a speed of $0.01 \mathrm{~mm} \mathrm{~s}^{-1}$. Subsequently, the specimen was loaded until sliding occurred, and the compression could be seen through an increased thickness or slight buckling. Finally, a tomography of the broken state was taken.

\section{Reconstruction and image processing}

The X-ray projections were reconstructed to spatial information at the facility. The reconstruction of one tomography produced a stack of 2048 subsequent slices of size $2048 \times 2048$ pixels each, representing the field of view $\left(3.7 \times 3.7 \times 3.7 \mathrm{~mm}^{3}\right)$ in these experiments (Figure 1d). Taking a tomography after every loading step, results were in a series of five to seven files for every specimen. First, data reduction was needed. As the field of view is larger than the smallest sample diameter of $1.4 \mathrm{~mm}$, the picture can be cropped, and the size therefore reduced by a factor 4 . Then, the failure region was determined, and only slices close to this region were considered for further evaluation, leading to another data reduction. To fit the samples to the wood-based coordinate systems with tangential, radial, and crosssectional directions, the stacks were realigned, so that the $x$ and $y$ axis in the figures represent the tangential and radial alignment, while the $z$ equals the subsequent longitudinal direction. Finally, the noise in the pictures caused by the absorption of the surrounding carbon fiber tube and air had to be eliminated. Those disturbances with a lower absorption than wood, as well as other nonsample-related effects, were reduced by approximating the absorption regions of wood and of the carbon fiber tube with histograms of an uncropped picture and a cropped one. When cropped, the percentage of surrounding area to wood drops significantly. This is visible in the histogram through a change in the ratio of the partly separated Gaussian curves for wood and air. Through this, a global threshold cropping the lower values can be approximated to clean the slices for a first impression of the suitability of the in situ measurements. To further reduce noise caused by movements of the sample during the tomography and remaining noise due to various effects, connected regions in the stacks were identified with MATLAB (The Mathworks, Inc., Natick, MA, USA), and small regions in the lumen related to noise were deleted. Figure 1e shows an example of a cleaned slice. Further, to identify the single tracheids, the area was cut to a small area surrounding the tracheid, and in the first and last slices, they were isolated. Wood rays and bordered pits were closed through a morphological close operation, and the lumen was identified. The space of the lumen was then dilated to show cell walls and connected features (wood rays, parts of connected tracheids).

The filtered stacks were used to identify the origin and development of failure areas. The resin channels turned out to be mostly undeformed; thus, they were used for distance measurements. In the process, the distance between two such structural elements in the center of the sample located at opposite ends was measured at the different loading steps. The displacement of the tracheids was determined by the change of first to last slice.

For the $3 \mathrm{D}$ presentation of the sample cuts and tracheids, the standard software package of ImageJ 1.42q (http://rsb.info.nih.gov/ij) was available.

\section{Results and discussion}

Two specimens of each sample shape were tested. As expected, geometry A and B broke at the transition of the cylindrical to 
the cone-shaped geometry with a small shear failure involved. Geometry C broke at the center nearly without detectable bending. So the behavior of one wood sample with the rotationally symmetric shape $\mathrm{C}$ will be described in detail. Six successive tomographies at increasing load levels were taken. The effects of increasing compression will be discussed based on tangential and radial reconstructions (Figure 3a-1) through

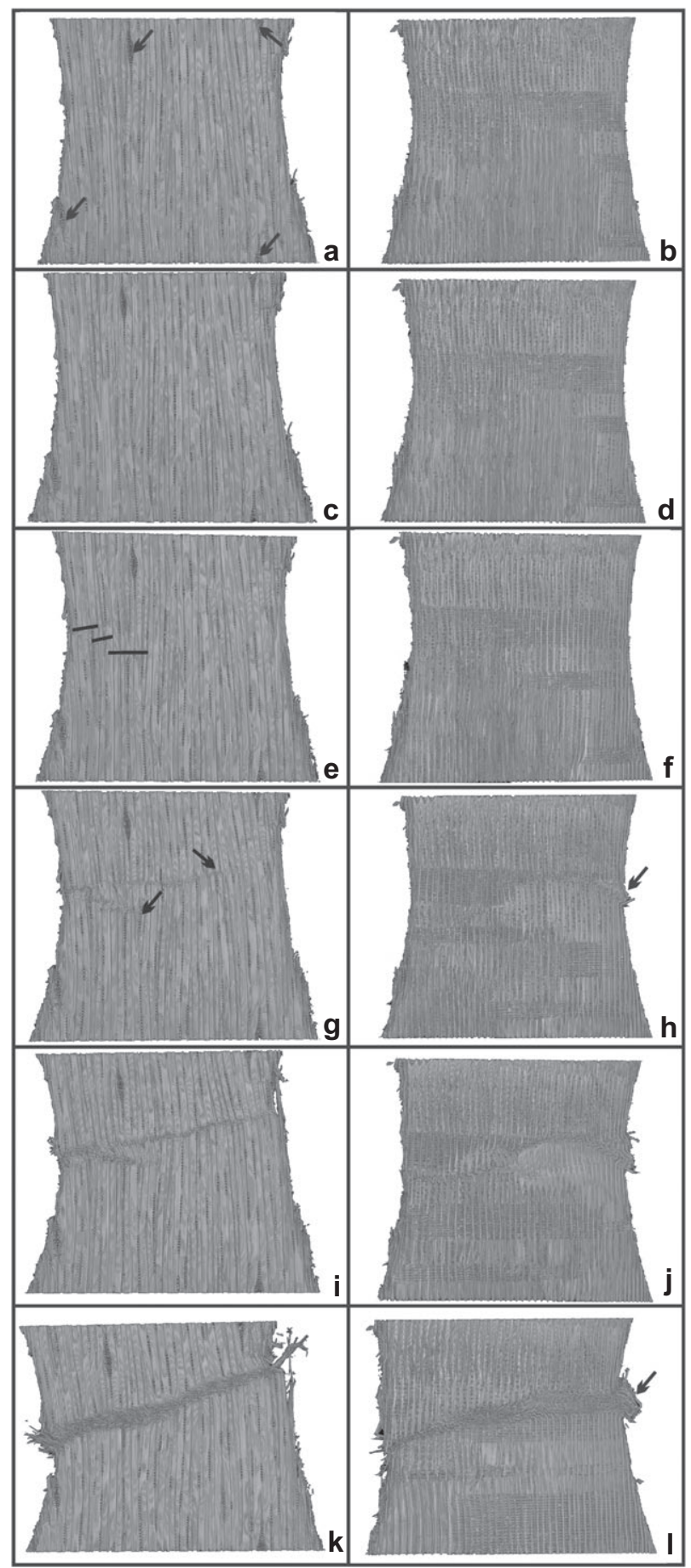

Figure 3 Successive tomographies of a sample at increasing force levels. Left column radial and right tangential view; (a) and (b) initial state, (c) to (1) 1. to 5. Step.
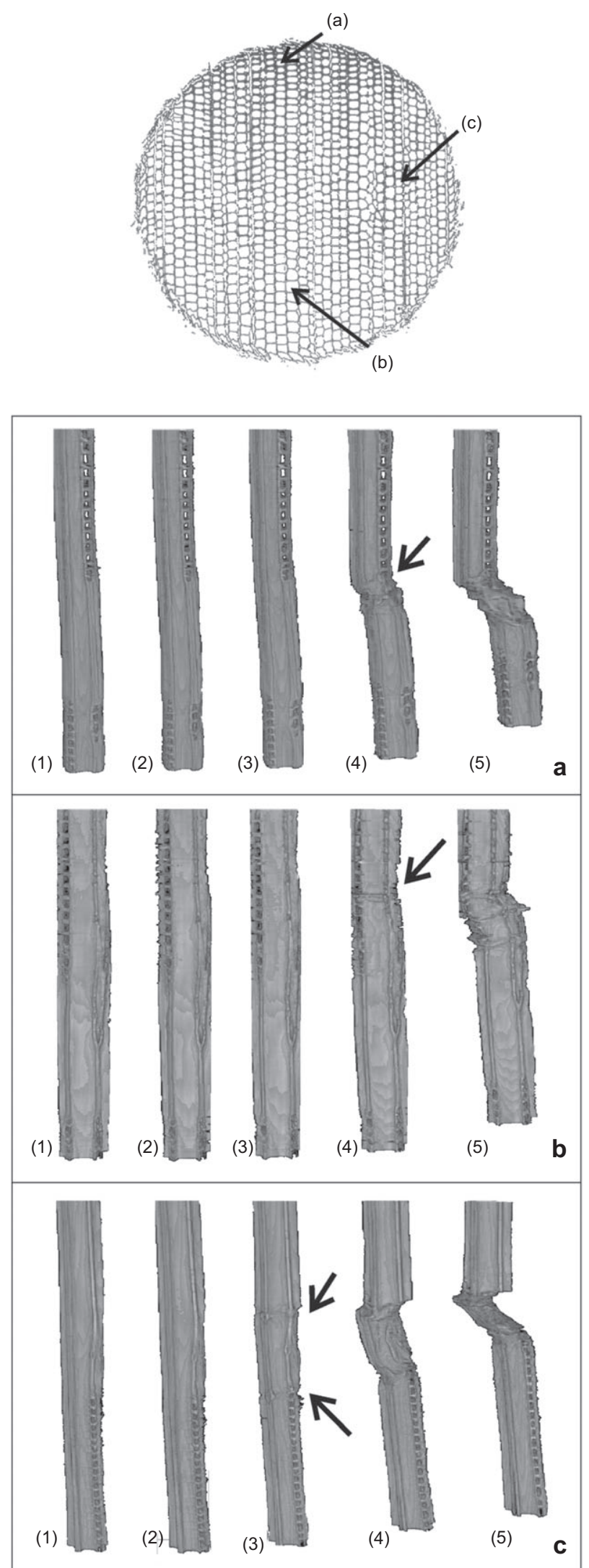

Figure 4 Deformation of single tracheids of (a) LW, (b) EW, and (c) between LW and EW. Initial state is presented in (1), 1.-4. compression steps in (2)-(5). 
the center corresponding to each loading step. The subsequent change of three single tracheids of the same sample is shown with Figure $4 \mathrm{a}-\mathrm{c}$. Their position can be seen in the cross section of Figure 4.

The initial, uncompressed (unloaded) state of the sample can be seen in the corresponding radial (Figure 3a, equal to the lower half of Figure 1e) and tangential (3b, equal to left half of Figure 1e) planes and serve as reference for the loaded stages. In this tomography, the basic structure of the sample can be described. In the center of the sample cell walls ranging from EW to LW, no complete growth ring is included (also in Figure 1e). Four radial resin channels (Figure 3a), partly filled with resin, can be seen. Defects due to machining are visible in the form of two to three compressed cells at the surface, with no premature damage in the inner regions. The three selected tracheids show no signs of predamage in their initial state (Figure 4a-c1).

After the first loading step (Figure $3 \mathrm{c}$ and d), the sample does not show signs of compression in the field of view. Accordingly, the single tracheids (Figure 4a-c2) correspond to the initial state $(4 \mathrm{a}-\mathrm{c} 1)$. Presumably, deformations happened in the elastic regime. The absence of displacements can also be explained by the fact that only half of the sample is in the field of view. Thus, compression could have occurred in parts outside of the recorded area. The sample was perhaps further pressed into the clamps and aligned. Furthermore, due to the long recording time of $11 \mathrm{~min}$, in comparison with the short relaxation time for small forces, elastic deformations could have been reversed.

After applying the next loading step, the sample shows first signs of plastic deformation that are not visible on the surface of the sample and limited to about a quarter of the cross section (Figure 3e, f). The displacement in the field of view is $0.004 \mathrm{~mm}$. Figure $3 \mathrm{f}$ shows no signs of compression due to the failure area not spanning the whole sample. The LW and the EW tracheids (Figure 4a-b3) close to the $3 \mathrm{f}$ cross section are equally compressed (Table 1 ), while the tangential shear is lower for the EW tracheids. In the middle of the sample at the left border in Figure 3e, the buckling of the first cells can be observed. The failure occurs in a stepped shape (indicated by the black lines) without a direct connection in this plane. These cells are the origin of a part of the failure line that subsequently develops because of the increasing compressive load. In Figure 4c3, a double buckling (equivalent Figure $3 \mathrm{~g}$ ) of the tracheids can be seen. The compression is lower than for the other tracheids. In contradiction to the expected outcome, the first collapsing cells were partly LW cells and not the less stable EW cells. One possible explanation is the machining and the subsequent damage at the surface of the sample where the LW cells are located. The failure area essentially shows mostly cell walls collapsed at one point.

When the load is further increased, the displacement from the reference state is $0.03 \mathrm{~mm}$. The failure line caused by buckling expands further and reaches over the middle of the samples' cross section (Figure $3 \mathrm{~g}$ and $\mathrm{h}$ ). The first failures connect to a failure line visible in Figure $3 \mathrm{~g}$ without further expanding in length and stopping at a wood ray crossing the line. A second failure line starts to develop above the first at an angle of $25^{\circ}$ to the other one at the surface. This second one crosses two thirds of the sample and nearly reaches the other end of the picture. The two failure areas connect at a small area where cells have buckled twice at different heights, as can be seen for tracheids of Figure $4 c 4$.

The top and bottom of the tracheids are displaced, while the middle part between the collapsing area is uncompressed, leading to a slightly lower compression (Table 1) than for the LW tracheids (Figure 4a4). In the tangential direction, a collective of compressed and deformed fibers start to push out at the edge of the specimen. The span of the failure area can partly be seen in Figure 3h, where the failure line spans the complete section with one connected line. The EW cell (Figure 4b4), situated close to the left end of Figure $3 \mathrm{~h}$, shows buckling. The relative shear is lower than for the other tracheids (Table 1). At this point, the behavior of the wood rays can also be seen. Where the failure area crosses a ray, it either bends (Figure $3 \mathrm{~g}$ ), or the upper and lower parts are shifted against each other with one cell row collapsing, while still maintaining their original orientation. The failure line did not cross a resin channel, which could be due to the higher stability of the resin or because of the positions. The force still increased for this compression step in relation to the previous one. Although failure continued and the maximum load observed was reached in this step, the compression failure could have happened in this or the following step. A slight blurring of the parts deforming could be due to a microdisplacement of these areas during the tomography due to the ongoing relaxation.

Further increasing the compression leads to the first failure area expanding until it spans the whole sample (Figure 3i, j). The thickness also increases as more cell walls collapse, and the failure areas begin to merge. This leads to a higher density in the corresponding area and stabilization of the two failure lines, consequently leading to a slipping plane and provoking

Table 1 Compression and displacement of upper against lower end of tracheids a-c of Figure 4.

\begin{tabular}{lccccccr}
\hline & \multicolumn{3}{c}{ Compression $(\mu \mathrm{m})$} & & \multicolumn{2}{c}{ Tangential displacement $(\mu \mathrm{m})$} \\
\cline { 2 - 3 } \multicolumn{1}{c}{ Cells } & Step 2 & Step 3 & Step 4 & & Step 2 & Step 3 & Step 4 \\
\hline LW tracheid (Figure 4a) & 7 & 56 & 120 & & 7 & 25 & 54 \\
EW tracheid (Figure 4b) & 7 & 12 & 60 & & 4 & 16 & 43 \\
Tracheid (Figure 4c) & 4 & 43 & 170 & & 7 & 25 & 54 \\
\hline
\end{tabular}


the cells between those areas to tilt relative to the cells outside the connecting area. The displacement of the sample is 0.09 $\mathrm{mm}$ and therefore twice as high compared to the difference between the third and fourth step. At this point, sliding begins to occur along the main failure area, and as the compression of the cells advances, they continue to push out of the surface. All tracheids are rapidly deformed (Figure 4a-c5). The tracheid in Figure 4c5 shows the highest deformation increase (Table 1) of nearly four times compared to the last step, mainly in the region between the failure lines. The only radial transformation of $0.007 \mathrm{~mm}$ can be observed for the LW tracheids.

For the last loading step, the traveling distance was increased leading to a deformation of $0.250 \mathrm{~mm}$. Basically, the mechanisms encountered in the last two steps are further intensified (Figure 3k, 1). Already collapsed cells continue to collapse further, and the two failure lines, which were separated in the last tomography, merge through a complete collapse of the cells between them. It forms a slightly broader failure area in the middle, which acts as a sliding plane. The sample breaks into two different sections along the failure line that slide against one another. Even in this state of load with high movement and high relaxation times, smaller structures like bordered pits and wood rays are still clearly visible.

\section{Conclusions}

In experiments done with SbTM and with the testing device constructed, the development of failure areas can be clearly seen, and the behavior of single tracheids can be observed. Cell structures like bordered pits stay recognizable under load. After the first step, the sample is still in the elastic range of mechanical response, and no displacement is visible. The first deformation can be seen originating from the border areas, possibly due to the weakened structure there. LW cells with their higher density collapse first. Further increasing the load entails an increment of failure area not only in one direction, instead of the failure area branches, and provides two layers. Subsequently, the main branch continues to develop and integrates the smaller one, until macroscopic failure of the sample occurs. During the whole loading process, only tracheids are deformed and broken, while resin channels remain unchanged. Wood rays are stable, until the load increases over a certain level and subsequently are completely compressed.

Despite its preliminary character, this study shows that the method is suitable for the observation of failure mechanisms of wood.

\section{Acknowledgments}

We want to thank the staff of the TOMCAT beamline at SLS in Villigen: Especially Andreas Isenegger and Gordan Mikuljan for their technical assistance in implementing the loading device and controls into the Tomcat System, as well as Federica Marone and Sarah Catherine Irvine for their assistance while using the beamline. Finally, we want to thank Peter Jenni of the mechanical workshop at
D-Baug for assembling the loading device. This work was supported by the European Cooperation in the field of scientific and technical research (COST, Action FP0802).

\section{References}

Badel, E., Delisee, C., Lux, J. (2008) 3D structural characterisation, deformation measurements and assessment of low-density wood fibreboard under compression: the use of X-ray microtomography. Compos. Sci. Technol. 68:1654-1663.

Butterfield, B.G., Meylan, B.A. Three-Dimensional Structure of Wood. Chapman and Hall, London and New York, 1980.

Dodd, J.D. (1948) On the shapes of cells in the cambial zone of Pinus silvestris L. Am. J. Bot. 35:666-682.

Forsberg, F., Mooser, R., Arnold, M., Hack, E., Wyss, P. (2008) 3D micro-scale deformations of wood in bending: synchrotron radiation muCT data analyzed with digital volume correlation. J. Struct. Biol. 164:255-262.

Frühmann, K., Burgert, I., Stanzl-Tschegg, S.E. (2003) Detection of the fracture path under tensile loads through in situ tests in an ESEM chamber. Holzforschung 57:326-332.

Groso, A., Abela, R., Stampanoni, M. (2006) Implementation of a fast method for high resolution phase contrast tomography. Opt. Express 14:8103-8110.

Hass, P., Wittel, F.K., McDonald, S.A., Marone, F., Stampanoni, M., Herrmann, H.J., Niemz, P. (2010) Pore space analysis of beech wood: the vessel network. Holzforschung 64:639-644.

Hofstetter, K., Hellmich, C., Eberhardsteiner, J. (2005) Development and experimental validation of a continuum micromechanics model for the elasticity of wood. Eur. J. Mech. A - Solid 24:1030-1053.

Jansen, S., Pletsers, A., Sano, Y. (2008) The effect of preparation techniques on SEM-imaging of pit membranes. IAWA J. 29:161-178.

Keunecke, D., Eder, M., Burgert, I., Niemz, P. (2008) Micromechanical properties of common yew (Taxus baccata) and Norway spruce (Picea abies) transition wood fibers subjected to longitudinal tension. J. Wood Sci. 54:420-422.

Mannes, D., Marone, F., Lehmann, E., Stampanoni, M., Niemz, P. (2010) Application areas of synchrotron radiation tomographic microscopy for wood research. Wood Sci. Technol. 44:67-84.

Müller, U., Gindl, W., Teischinger, A. (2003) Effects of cell anatomy on the plastic and elastic behaviour of different wood species loaded perpendicular to grain. IAWA J. 24:117-128.

Scholz, G., Zauer, M., Van den Bulcke, J., Van Loo, D., Pfriem, A., Van Acker, J., Militz, H. (2010) Investigation on wax-impregnated wood. Part 2: Study of void spaces filled with air by $\mathrm{He}$ pycnometry, $\mathrm{Hg}$ intrusion porosimetry, and 3D X-ray imaging. Holzforschung 64:587-593.

Sippola, M., Frühmann, K. (2002) In situ longitudinal tensile tests of pine wood in an environmental scanning electron microscope. Holzforschung 56:669-675.

Stampanoni, M., Groso, A., Isenegger, A., Mikuljan, G., Chen, Q., Bertrand, A., Henein, S., Betemps, R., Frommherz, U., Bohler, P., Meister, D., Lange, M., Abela, R. (2006a) Trends in synchrotron-based tomographic imaging: the SLS experience. 5th Conference on Developments in X-ray Tomography. Ed. Bonse, U. San Diego, CA, Vol. 6318. pp. U199-U212.

Stampanoni, M., Groso, A., Isenegger, A., Mikuljan, G., Chen, Q., Meister, D., Lange, M., Betemps, R., Henein, S., Abela, R. (2006b) TOMCAT: a beamline for TOmographic Microscopy and Coherent rAdiology experimenTs. 9th International Conference 
on Synchrotron Radiation Instrumentation (SRI 2006). Eds. Choi, J.Y., Rah, S. Daegu. South Korea. Vol. 879. pp. 848-851.

Steppe, K., Cnudde, V., Girard, C., Lemeur, R., Cnudde, J.P., Jacobs, P. (2004) Use of X-ray computed microtomography for noninvasive determination of wood anatomical characteristics. J. Struct. Biol. 148:11-21.

Tabarsa, T., Chui, Y.H. (2000) Stress-strain response of wood under radial compression. Part I. Test method and influences of cellular properties. Wood Fiber Sci. 32:144-152.

Trtik, P., Dual, J., Keunecke, D., Mannes, D., Niemz, P., Stahli, P., Kaestner, A., Groso, A., Stampanoni, M. (2007) 3D imaging of microstructure of spruce wood. J. Struct Biol. 159:46-55.
Vasic, S., Stanzl-Tschegg, S. (2006) Experimental and numerical investigation of wood fracture mechanisms at different humidity levels. 7th World Congress on Computational Mechanics. Los Angeles, CA. Vol. 61. pp. 367-374.

Wagenführ, R. Holzatlas. Fachbuchverlag Leipzig/Carl Hanser Verlag, Leipzig, 2007.

Walther, T., Thoemen, H. (2009) Synchrotron X-ray microtomography and 3D image analysis of medium density fiberboard (MDF). Holzforschung 63:581-587.

Received September 26, 2011. Accepted May 2, 2012. Previously published online June 15, 2012. 